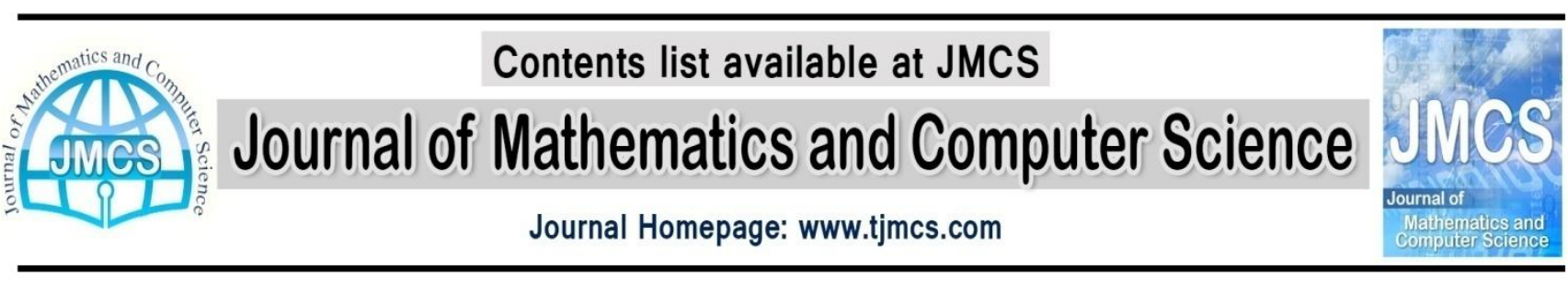

\title{
Thermal Control of Building Using Latent Heat Storage South Wall
}

\author{
Mustapha Faraji ${ }^{*}$, Mustapha E. Alami, Mostafa Najam \\ Thermal Group, LPMMAT Laboratory, Physics Department- Faculty of Sciences Ain Chock, PO 5366 \\ Mâarif, Hassan II University, Casablanca-Morocco \\ *farajimustapha@yahoo.fr
}

Article history:

Received March 2014

Accepted April 2014

Available online May 2014

\begin{abstract}
The aim of the present work is to study the thermal performance of a composite wall used for heating management of building. The solar energy absorbed by the wall is stored in a phase change material (PCM). The advantage of using this heating strategy is that PCMs are able to melt and absorb a high amount of diurnal solar radiations and release it to the room during the night to provide passive nocturnal heating. A one-dimensional mathematical model was developed in order to analyze and optimize the proposed latent heat storage wall. Numerical investigations were conducted in order to examine the effects of the PCM position and the PCM material properties on the thermal behavior of the proposed wall. It was found that, when the PCM layer is closer to the inner face of the wall, thermal comfort conditions are considerably improved compared to a concrete wall without PCM. The good PCM choice is satisfied when the material melts completely before the sunset and re-solidifies completely before the sunrise. Phase change materials that have a better thermal conductivity lead to a significant reduction of the building energy consumption.
\end{abstract}

Keywords: Building, Mathematical model, PCM, Latent heat, Thermal control

\section{Introduction}

PCM integrated building components could have a high potential for successful adoption in Mediterranean buildings because of their ability to reduce energy consumption for space conditioning and reduce peak loads. Other anticipated advantages of a phase change material (PCM) are occupant comfort improvement and compatibility with common buildings. In the recent years the research on the use of the PCM is increasingly being considered for building energy applications. This concept couples the advantages of the high latent heat capability of PCM with an efficient thermal design of the wall. During the last 30 years, few PCM products to be used in buildings appeared in the market. Such a technology is now being commercially employed. A PCM layer in a wall will melt at a constant temperature when the exterior temperature rises, and solidify when the exterior temperature goes 
down, in such a way that the indoor could become relatively blind to the exterior conditions. PCM presents difficulties to be melted by direct solar radiation because of its the poor heat conductivity. On the other hand, the walls and ceilings of a building offer large areas for passive heat transfer within every zone of the building [1]. In the literature, development and testing were conducted for prototypes of PCM wallboard and PCM/concrete systems, with particular interest in peak load shifting and solar energy utilization [2,3]. In building-integrated applications, PCMs have been incorporated into gypsum wallboards to provide passive energy storage. Several authors investigated the various methods for impregnating gypsum and other PCMs in wallboards [4-6]. Faraji [7] studied composite mortar/phase change material wall. Parametric simulations of the thermal performance of the wall were performed to account for the influences of the melting point of the PCM layer. The results show that, incorporating the phase change material with appropriate melting point can improve the thermal performances of the wall. Zhang et al. [8] presented the development of a thermally enhanced wall that reduces peak airconditioning demand in residential buildings. Berroug et al. [9] analyzed the thermal performance of a north wall made with hydrate salt phase change material as a storage medium in east-west oriented greenhouse. A numerical study has been developed to investigate the impact of the PCM on greenhouse temperature. Results show that, with an equivalent to $32.4 \mathrm{~kg}$ of PCM per square meter of the greenhouse area, temperature of inside air were found to be $6^{\circ} \mathrm{C}$ more at night in winter period with less fluctuations. Athienities and Chen [10] investigated the transient heat transfer in floor/PCM heating systems. Experimental and simulation results for an outdoor test room reveal that a local floor/PCM temperature is $8^{\circ} \mathrm{C}$ higher than that in the ordinary floor. Lin et al. [11] put forward a new kind of underfloor electric heating system with phase change material plates. Ismail and Henriquez [12] proposed a different concept for thermally effective windows using a PCM moving curtain. In another paper, Athienitis et al. [13] conducted an experimental study in a full scale outdoor test room with PCM gypsum board. Brousseau and Lacroix [14] carried out a numerical analysis of the cyclic behavior of alternative melting and freezing in a multi-plate latent heat energy storage. In the present paper, a detailed study of the thermal performance of a wall/phase change material system for building thermal energy management is analyzed and discussed. The thermal response to the realistic boundary conditions and using temperature ranges and material properties that are common in buildings are investigated. The effect of the PCM layer position and PCM properties are analyzed for the cold period (January). The thermal performance is compared to an ordinary wall in term of thermal load leveling and heating potential to determine the potential benefit of such a composite wall.

\section{Mathematical model}

Fig. 1 shows the physical system studied in the present work. It consists of a sandwiched wall made with three layers. The outside and the inside layers are concrete, the medium is PCM. The total thickness of the wall is $L=20 \mathrm{~cm}$ and the PCM layer is located at variable positions $x_{m}$. The thickness of the PCM layer is kept constant at $e_{m}=2 \mathrm{~cm}$. The wall corresponding thermal properties are given in Table 1. The composite PCM wall was initially at a uniform temperature, $T_{\text {ini }}=16{ }^{\circ} \mathrm{C}$. The boundary conditions on the outer surface of wall are due to the combined effects of solar radiation and ambient air convection. Meteorological data for every one hour in Casablanca city, Morocco $\left(33^{\circ} 36^{\prime} \mathrm{N}, 07^{\circ} 36^{\prime} \mathrm{W}\right)$ are used. For natural convection, the average heat transfer coefficient on the outer surface is calculated based on the prevailing velocity of the wind, $h_{0}=20 \mathrm{~W} / \mathrm{mK}$. For indoor surface of the concrete boundary conditions, natural convection heat transfer coefficient is also considered, $h_{i}=5 \mathrm{~W} / \mathrm{mK}$. During the day (charging period) the melting process is due to the combination of solar radiations absorption, $\gamma Q_{\text {ext }}$, and outdoor air convective heat flux, while, during the night (discharging period) the solidification process starts after the sunset when there are no solar radiations, the wall loses it energy to the ambient by radiative $Q_{w, r a d}$ and convective heat transfer. 
Before presenting the equations that govern the heat transfer process occurring in the system, some assumptions were made in order to simplify its resolution. These assumptions are given as follows:

- thermal properties are constant and not varying with respect to temperature;

- end effects are neglected;

- interfacial resistances are negligible;

- heat transfer through the wall is assumed $1 \mathrm{D}$;

- buoyancy induced flow in the melted PCM is neglected.

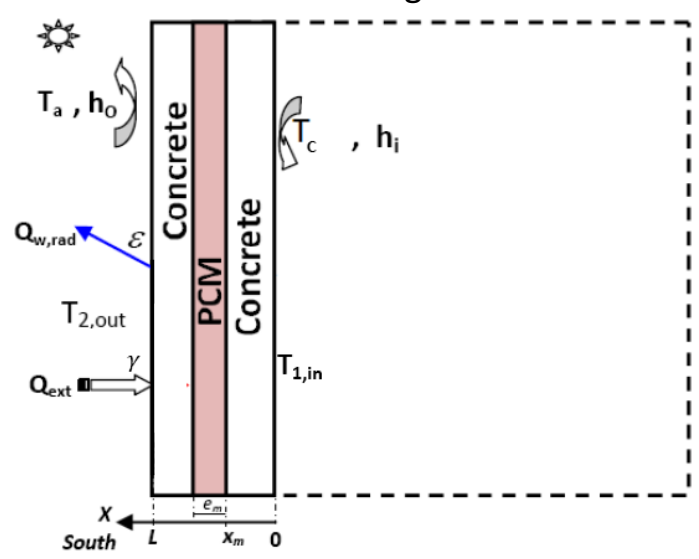

Fig. 1: Physical model

\section{- Governing Equations}

The energy transport in composite concrete/PCM may be written using the enthalpy formulation [15]:

$$
\frac{\partial H}{\partial t}=\nabla(k \nabla T)
$$

where,

$$
H(T)=h(T)+\rho \lambda f \Delta H_{f}
$$

and

$$
h(T)=h\left(T_{m}\right)+\int_{T_{m}}^{T} \rho c_{p} d T
$$

$\lambda=1$ in PCM and $\lambda=0$ in concrete layers.

using sensible enthalpy $\mathrm{h}, \mathrm{Eq}(1)$ is rewritten as:

$$
\frac{\partial h}{\partial t}=\alpha \frac{\partial^{2} h}{\partial x^{2}}-\rho \lambda \Delta H_{f} \frac{\partial f}{\partial t}
$$

The liquid fraction $f$ in the PCM layer is estimated as: 


$$
f=\left\{\begin{array}{lrr}
1 & \text { if } & T>T_{m} \\
0 & \text { if } & T_{m}<T \\
0<f<1 & \text { if } T=T_{m}
\end{array}\right.
$$

The continuity of the temperature and heat flux density are used at the interfaces concrete/PCM. The thermal properties at interfaces were obtained by the following relations:

$$
\begin{aligned}
& k_{i}=\frac{k_{+} k_{-}\left(\delta_{-}+\delta_{+}\right)}{k_{+} \delta_{-}+k_{-} \delta_{+}}, k_{m}=f k_{l}+(1-f) k_{s}, \\
& \rho c_{p}=f\left(\rho c_{p}\right)_{l}+(1-f)\left(\rho c_{p}\right)_{s}
\end{aligned}
$$

where $\delta_{+}$is the distance between the interface and the first node inside the PCM region and $\delta$ is the

\begin{tabular}{|c|c|c|c|}
\hline Material & Organic PCM & Hydrate Salt PCM & Concrete \\
\hline$T_{m}\left({ }^{\circ} \mathrm{C}\right)$ & 16 & 21 & - \\
\hline$\Delta H_{f}(\mathrm{~kJ} / \mathrm{kg})$ & 148.5 & 150 & - \\
\hline$\rho\left(\mathrm{kg} / \mathrm{m}^{3}\right)$ & $\begin{array}{c}981 \text { (Solid) } \\
862 \text { (Liquid) }\end{array}$ & 800 & 2200 \\
\hline$k(\mathrm{~W} / \mathrm{mK})$ & 0.145 & 0.54 & 1.5 \\
\hline$c_{p}(\mathrm{~J} / \mathrm{kg} \mathrm{K})$ & $\begin{array}{l}1460 \text { (Solid) } \\
2130 \text { (Liquid) }\end{array}$ & 680 & 838 \\
\hline$\gamma$ & - & - & 0.9 \\
\hline$\varepsilon$ & - & - & 0.85 \\
\hline
\end{tabular}
distance between the interface and the first node inside the concrete layer.

Table 1: Thermophysical properties $[1,18]$

\section{- Boundary Conditions}

- at $x=0$ :

$$
-\left.k \frac{\partial T}{\partial x}\right|_{x=0}=h_{i}\left(T_{c}-T\right)
$$

- at $x=L$ :

$$
-\left.k \frac{\partial T}{\partial x}\right|_{x=L}=h_{o}\left(T_{a}-T\right)+Q_{w, r a d}+\gamma Q_{e x t}
$$

where,

$$
Q_{w, r a d}=\sigma \varepsilon F\left(T_{s k y}^{4}-T^{4}\right)=h_{s k y}^{r}\left(T_{a}-T\right)
$$

here, the sky is considered as black body at $T_{s k y}\left({ }^{\circ} \mathrm{C}\right)[16]$ :

$$
T_{s k y}=0.0552 \times\left(T_{a}+273.15\right)^{1.5}-273.15
$$

The irradiative heat transfer coefficient $h_{s k y}^{r}$ is given by: 


$$
h_{s k y}^{r}=\frac{\sigma \varepsilon\left(T_{s k y}^{4}-T^{4}\right)}{T_{a}-T}
$$

the shape factor $F$ is assumed to be equal to one.

-Heat flux at interfaces, $x=x_{m}$ and $x=x_{m}+e_{m}$, between PCM and concrete is evaluated as:

$$
q_{i}^{\prime \prime} \approx \frac{k_{+} k_{-}}{k_{+} \delta_{-}+k_{-} \delta_{+}}\left(T_{+}-T_{-}\right)
$$

\section{- Numerical Scheme}

The governing equations were integrated using finite volume technique [17]. It should be noted that the obtained equations are non linear because the irradiative transfer coefficient, $h_{s k y}^{r}$, can appear with the term, $T^{4}$, in the irradiative component. To resolve this problem iteratively, the above terms must be considered constant within each time step. The new value of the obtained temperature will be used in none linear irradiative heat transfer coefficient. The finite difference equation for the PCM layer is obtained on integrating Eq. (4) over each control volume.

$$
\int_{x_{w}}^{x_{e}} \frac{\partial}{\partial x}\left(\alpha \frac{\partial h}{\partial x}\right) d x=\left[\left(\alpha \frac{\partial h}{\partial x}\right)_{e}-\left(\alpha \frac{\partial h}{\partial x}\right)_{w}\right]
$$

Heat fluxes densities are linearized as follow:

$$
\left(\alpha \frac{\partial h}{\partial x}\right)_{e} \approx \alpha_{e}\left(\frac{h_{E}-h_{P}}{x_{E}-x_{P}}\right),\left(\alpha \frac{\partial h}{\partial x}\right)_{w} \approx \alpha_{w}\left(\frac{h_{P}-h_{W}}{x_{P}-x_{W}}\right)
$$

$P, E$ and $W$ denote the centre, east face and west face of control volume. Discretization of Eq. (4) leads to the following scheme:

$$
a_{W} h_{W}+a_{P} h_{P}+a_{E} h_{E}=b
$$

where,

$$
\left\{\begin{array}{l}
a_{w}=-\frac{\Delta t}{(\Delta x)^{2}} \alpha_{w}, a_{E}=-\frac{\Delta t}{(\Delta x)^{2}} \alpha_{e} \\
a_{p}=1-a_{E}-a_{w}, b=h_{P}^{0}+\rho \lambda \Delta H_{f}\left(f_{p}^{0}-f_{P}\right)
\end{array}\right.
$$

Eq. (14) has been solved, for each time step, using a tri-diagonal matrix algorithm (TDMA). The central feature of the present fixed grid enthalpy method is the source term $b$. Here, $h_{p}$ and $f$ refer to the enthalpy and the melt fraction, respectively, from the previous time step. The source term $b$ keeps track of the latent heat evolution, and its driving element is the melt fraction. Its value is determined iteratively from the solution of the enthalpy equation. Hence, after the $(n+1)^{\text {th }}$ numerical solution of the enthalpy equation of the $P^{\text {th }}$ node, Eq. (14) may be rearranged as:

$$
a_{P} h_{P}=-a_{W} h_{W}-a_{E} h_{E}+h_{P}^{0}+\rho \lambda \Delta H_{f}\left(f_{P}^{0}-f_{P}^{(n)}\right)
$$

If phase change is occurring about the $P^{\text {th }}$ node (i.e. $\left.0<f<1\right)$, the $(n+1)^{\text {th }}$ estimate of the melt fraction needs to be updated such that the left side of Eq. (16) is zero: 


$$
0=-a_{W} h_{W}-a_{E} h_{E}+h_{P}^{0}+\rho \lambda \Delta H_{f}\left(f_{P}^{o}-f_{P}^{(n+1)}\right)
$$

hence,

$$
f_{p}^{(n+1)}=f_{p}^{(n)}+\frac{a_{p}}{\rho \Delta H_{f}} h_{p}
$$

The melt fraction update Eq. (18) is applied at every node after the $(n+1)^{\text {th }}$ solution of Eq. (14) for sensible volumetric enthalpy $h$, along with under/over corrections:

$$
\text { if } f>l \text { then } f=1 \text { (liquid), if } f<0 \text { then } f=0 \text { (solid) }
$$

The convergence of the calculus was declared, at each time step, when a criterion based on the energy conservation principle was satisfied. A grid and time step refinement was carried out and showed that the time step of $60 \mathrm{~s}$ and a size grid of 50 nodes were found to be adequate for all the computations. A self-Fortran computer code was developed in order to implement the above numerical method.

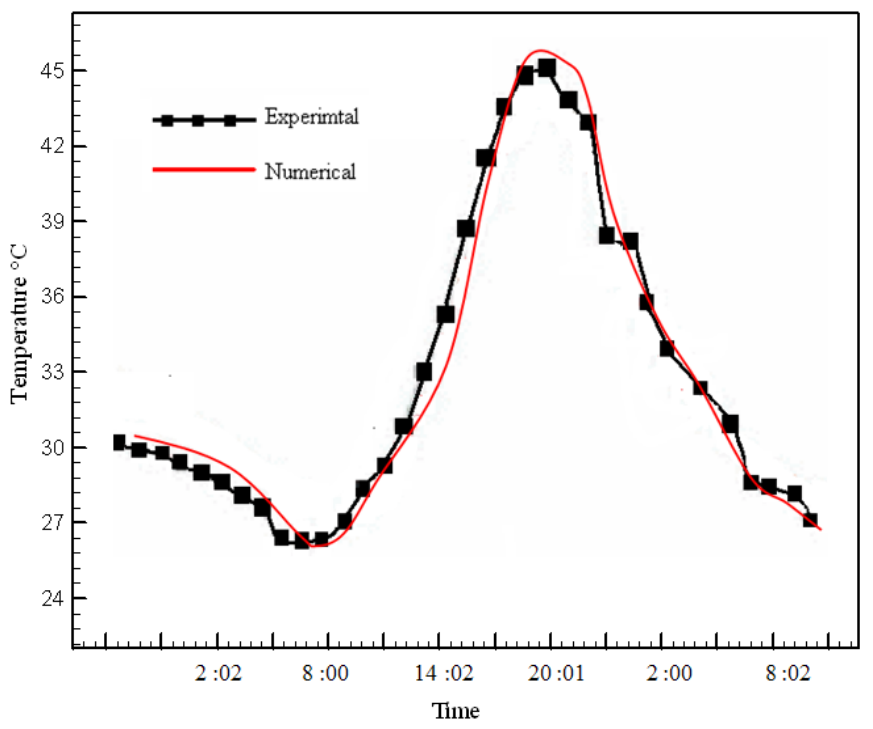

Fig. 2: Comparison between numerical and experimental [3] inner south wall temperatures

\section{- Validation}

In order to carry out the numerical investigations for the system presented in this study, a personal computer program was implemented in Fortran Language. Before conducting such numerical simulations, the computer program was used for validation against experimental data obtained by Zhuang et al. [3]. The experimental setup consists of a fabric integrated PCM. We focused on the south oriented PCM wall inner temperature data. The wall is made with three layers, from out to in, $5 \mathrm{~mm}$ veneer, $10 \mathrm{~mm}$ organic $\mathrm{PCM}$ with melting point of $40^{\circ} \mathrm{C}$ and $50 \mathrm{~mm}$ of EPS. Thermal conductivities of veneer, PCM and EPS foam are $0.17,0.04$ and $0.3 \mathrm{~W} / \mathrm{mK}$ respectively. The wall is subjected to the indoor convective heat transfer, $h_{i}=8.7 \mathrm{~W} / \mathrm{m}^{2} \mathrm{~K}$ and outer heat transfer coefficient, $h_{o}=23 \mathrm{~W} / \mathrm{m}^{2} \mathrm{~K}$. The test cell is located at Chongqing city-China. After a grid refinement, the numerical code was readapted to the 
setup conditions. The dry bulb temperature data file of Chongqing area is used in the simulation [19]. A comparison between numerical and experimental inner south wall temperature is sketched in Fig. 2 . The weather data available in the experiment are 36 hours between 8/22/2007 and 8/23/2007. It can be seen that, taking into account the complexity of the phenomenon, there is a satisfactory agreement between the present and published experimental data, and the maximum deviation was found less than $3 \%$. The concordance is better during the discharging period, between $17 \mathrm{~h} 00$ and $08 \mathrm{~h} 00$, when there are no solar radiations, and there is only convective heat transfer mode at ambient temperature.

\section{Results and discussion}

Fig. 3 shows the time wise variation of the ambient temperature, $T_{a}$, during typical days representing the cold period of the year (winter -January in Casablanca-Morocco, 33 $36^{\prime} \mathrm{N}, 07^{\circ} 36^{\prime} \mathrm{W}$ ). Ambient temperature rises due to the sunrise and falls during the night. This oscillatory phenomenon (increase followed by a decrease) is due to the alternating day/night every 24 hours. The minimum temperatures are obtained during the night. On average, temperatures minima and maxima range between $5{ }^{\circ} \mathrm{C}$ and $18{ }^{\circ} \mathrm{C}$ during the month, respectively, and the ambient temperature swing between these extreme. Radiations remain zero during the night and increase in the following day. Fig. 3 shows also the evolution of the global solar radiations, $Q_{\text {ext }}$, received by a south oriented vertical wall for typical days during January. The radiation is zero during the first 6 hours of every day and increases with the sunrise which causes the ambient temperature increase. Solar radiation reaches a maximum value $\left(720 \mathrm{~W} / \mathrm{m}^{2}\right)$ between solar noon and $15 \mathrm{~h} 00$ and falls to $0 \mathrm{~W} / \mathrm{m}^{2}$ at $18 \mathrm{~h} 00$ which present the sunset (cancellation of solar radiations). Solar radiations remain zero during the night and increase in the following day. Casablanca climate is characterized by severe temperature fluctuations and lower values of temperature are reached at night. None thermally controlled buildings will use more active heating systems during January in Casablanca- Morocco $\left(33^{\circ} 36^{\prime} \mathrm{N}, 07^{\circ} 36^{\prime} \mathrm{W}\right)$.

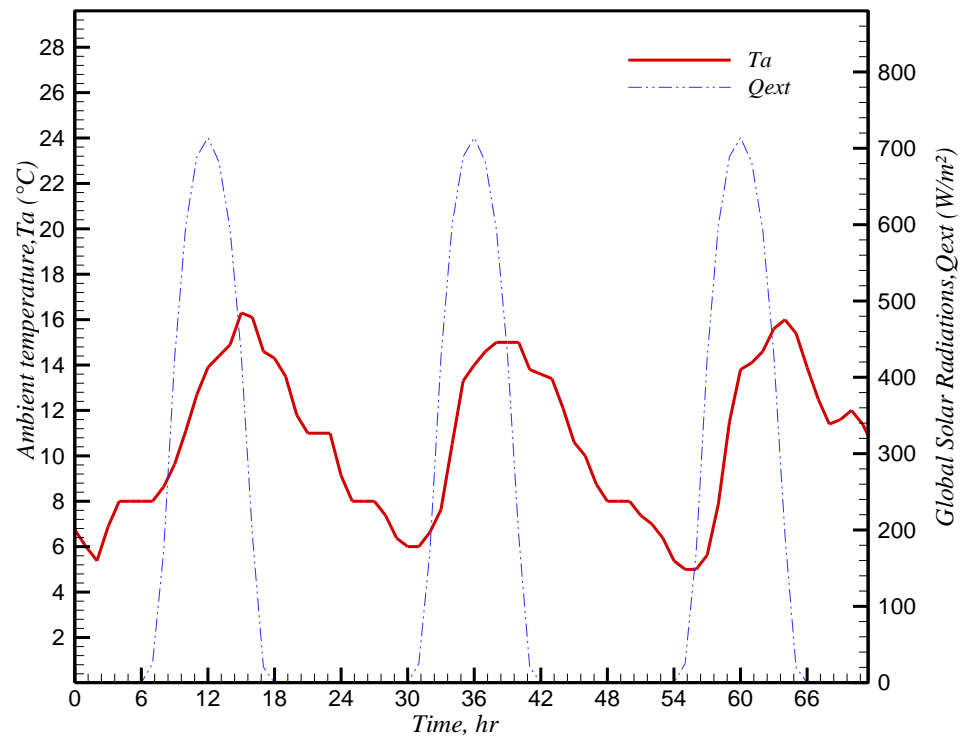

Fig. 3: Time wise variations of the ambient temperature, $T_{a}$, and the global solar radiations, $Q_{\text {ext, }}$ received by a south oriented vertical wall, (January- Casablanca, Morocco $33^{\circ} 36^{\prime} \mathrm{N}, 07^{\circ} 36^{\prime} \mathrm{W}$ ) 


\section{- Ordinary wall (Concrete without PCM)}

Fig. 4 shows the time wise variation of the temperature of the external and internal faces of a south faced ordinary $20 \mathrm{~cm}$ thick concrete wall (without PCM) during the colder month (January, CasablancaMorocco, $33^{\circ} 36^{\prime} \mathrm{N}, 07^{\circ} 36^{\prime} \mathrm{W}$ ). Thermal properties of the wall are summarized in Table 1 . Analysis of Fig. 4 shows that, during the night, ambient temperature decreases below the comfort temperature $\left(T_{c}=22\right.$ ${ }^{\circ} \mathrm{C}$ ) and provokes the decrease in the temperatures of the outer and inner wall faces. Between 06h00 and solar noon (13h00), solar radiations increases. The outside and the inner wall temperatures increase with some delay due to the concrete thermal inertia. These variations influence the interior house temperature. Note that the inner face temperature can exceed $27^{\circ} \mathrm{C}$ in a day this value is greater than the reference comfort temperature due to the sensible heating (see Fig. 5). The ambient temperature varies between $5{ }^{\circ} \mathrm{C}$ and $16{ }^{\circ} \mathrm{C}$ and provokes fluctuations of the external face temperature. Outer wall temperature variation is due to the solar radiations absorbed by the concrete $(\gamma=0.8)$ combined with convective heat flux. The nocturnal temperature of the inner face is greater than $16{ }^{\circ} \mathrm{C}$. This relatively higher value of inner nocturnal temperatures is due to the natural convective heat transfer between the inner face and inside air combined to the discharging of the sensible heat accumulated during the day in concrete, as illustrated in Fig. 5. The temperature minima achieved by the inner face is less than the comfort reference value $\left(T_{c}=22{ }^{\circ} \mathrm{C}\right)$ and inner temperature fluctuates. These none comfort conditions are none favorable for the occupants of the light weight building. So it is crucial to operate the HVACs system during winter in Casablanca- Morocco.

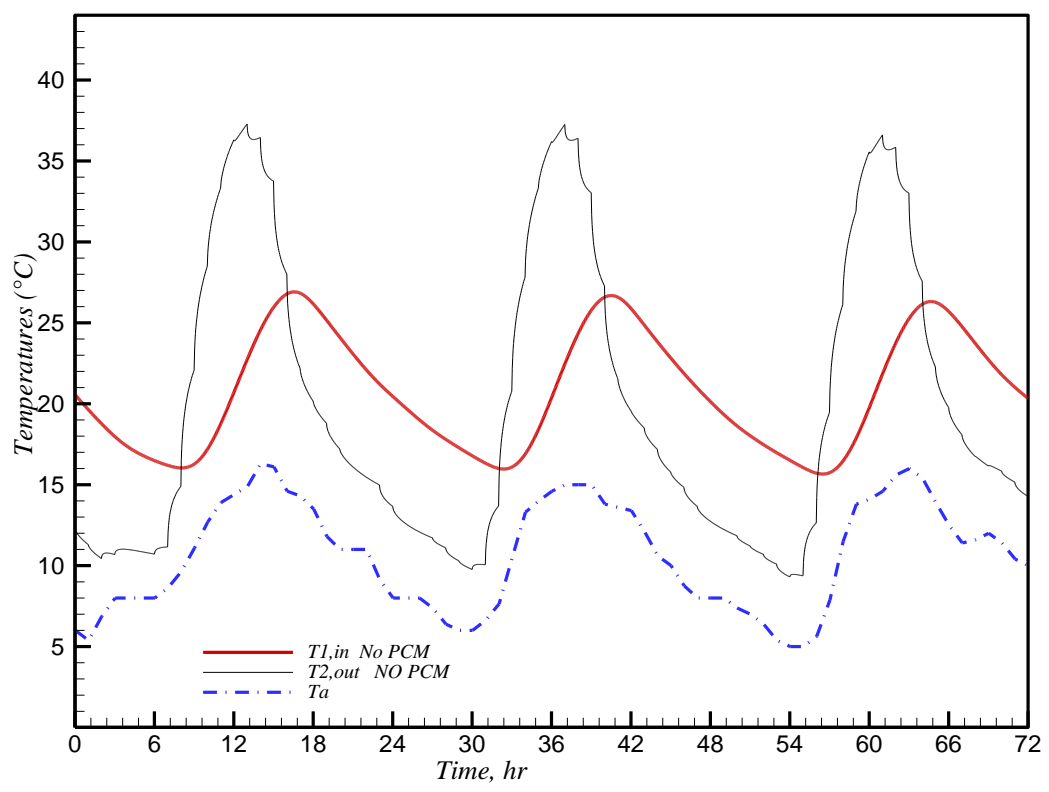

Fig. 4: Time wise variation of the external temperature, $T_{2, \text { out }}$, and internal temperature, $T_{1, i n}$, for an ordinary concrete wall (without PCM) 


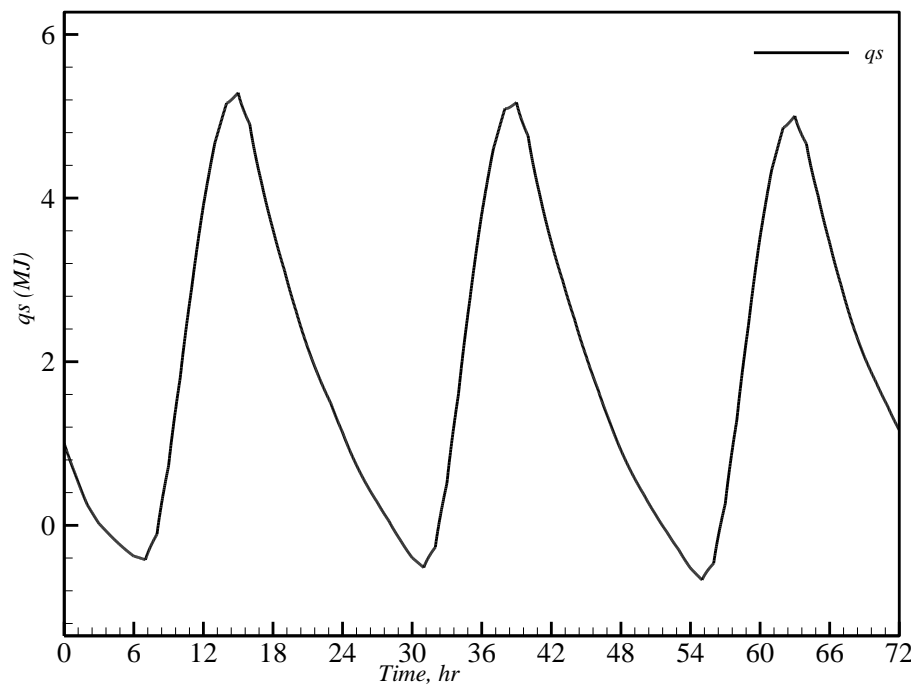

Fig. 5: Sensible heat storage for an ordinary wall (without PCM)

\section{- Composite wall (Concrete with PCM)}

Fig. 6 compares the thermal behavior of the ordinary wall and the composite wall with Organic PCM, $T_{m}=16^{\circ} \mathrm{C}$ (Table 1). The PCM layer is located at position $x_{m}=15 \mathrm{~mm}$. Data analysis shows that the inside wall temperature increases from $18.4{ }^{\circ} \mathrm{C}$ to $23.5^{\circ} \mathrm{C}$ and from $16{ }^{\circ} \mathrm{C}$ to $27{ }^{\circ} \mathrm{C}$, for wall/PCM and an ordinary concrete wall, respectively. The ambient temperature varies between $5^{\circ} \mathrm{C}$ to $15{ }^{\circ} \mathrm{C} \mathrm{(Fig.} \mathrm{3),} \mathrm{but}$ the PCM layer receives also a heat flux due to the solar radiations absorbed by the concrete $(\gamma=0.8)$ combined with convective heat flux that increases the PCM temperature to the melting point $\left(T_{m}=16\right.$ ${ }^{\circ} \mathrm{C}$ ). Remind that, Sensible heat storage stops and latent heat storage starts (Fig. 7) and, as a result, a first layer of the liquid phase appears $(f>0)$ and the latent heat storage develops with fusion process. For the PCM wall, the slop of T curve weakens during the phase change process because melting and solidification occur at constant temperature. The increase of solar radiation accumulates sensible heat storage in concrete and latent heat in PCM layer. The composite wall can be considered as an important storage device. The excess of heat is stored in the wall with less temperature variation until the full melting of PCM $(f=1)$. The stored heat during a day is used for heating needs in the following night.

Fig. 6 shows also that, the ambient temperature decreases after reaching a maximum. The PCM is totally melted at $11 \mathrm{~h} 00(f=1)$ and the sensible heating continue and leads to the increase of wall face temperature between $11 \mathrm{~h} 00$ and $17 \mathrm{~h} 00$. This result is confirmed by Fig. 7 which gives the latent, $q_{L}$, and sensible heat, $q_{s}$, storage variations. Analysis of such figure shows that, $q_{L}$, is more important than, $q_{s}$, and remains constant between $11 \mathrm{~h} 00$ and $17 \mathrm{~h} 00(f=1)$. The overheating of the liquid PCM layer is due to the raise of the sensible heat storage during that period and, therefore, leads to the increase of the wall temperature. This process continues 10 hours until the decrease of liquid fraction. The discharging process activates at $21 \mathrm{~h} 00$ and the inner wall temperature falls after a certain delay due to the thermal inertia and to the weak value of its thermal conductivity. Note that minimum temperature reached in case of the wall with PCM is clearly greater than that achieved without PCM because the shrink of the wall temperature is shifted by the use of the important stored latent heat. 
PCM solidify and melts periodically and the stored latent heat, $q_{L}$, varies between $5 \mathrm{MJ}$ and $45 \mathrm{MJ}$. Day/night cycles allow for charging/discharging of the PCM and wall temperature varies from $18.4{ }^{\circ} \mathrm{C}$ to $23.5^{\circ} \mathrm{C}$. The fluctuation intensity of the inner temperature (concrete with PCM) decreases with the development of the latent heat of fusion. The accumulated heat during the melting processes added to the overheating of the liquid PCM leads to the enhancement of the inner temperature during the night. The latent heat stored in the wall/PCM shifts the fast decrease of the temperature during the night. It is clear that the inside temperature of the PCM concrete wall is less fluctuating. Less thermal gradient occurs and the nocturnal temperature of the inner face is relatively high (days and nights) comparatively with the values achieved without PCM. The PCM wall achieves more efficient in thermal insulation and increases the thermal efficiency of the building during the coldest period of the year.

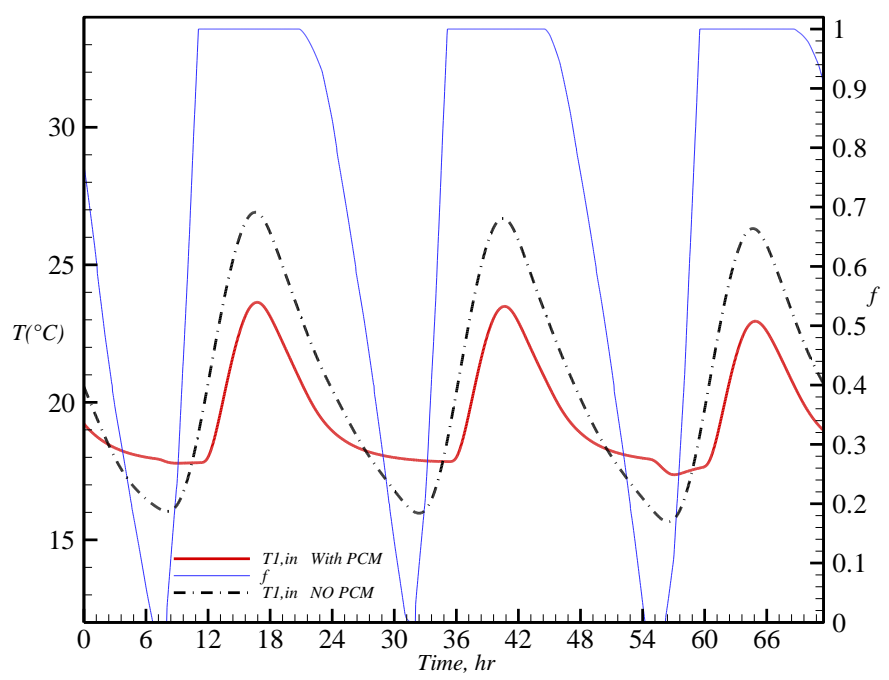

Fig. 6: Variations of the inner wall temperature, $T_{1, i n}$ and liquid fraction, $f$

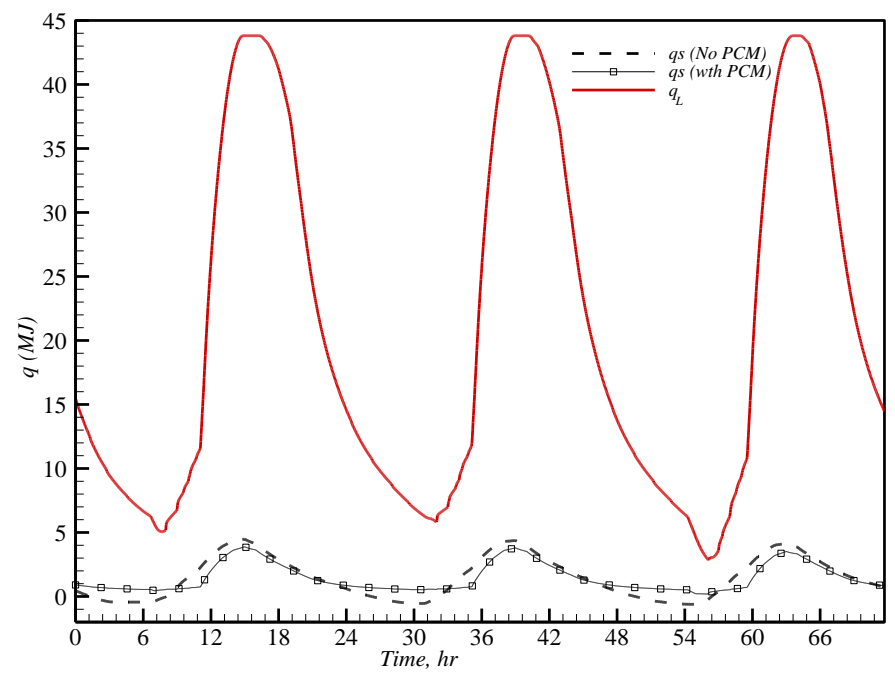

Fig. 7: Variations of the latent heat, $q_{L}$, and sensible heat, $q_{s}$ 
Above, The PCM layer was set close to the inner face of the wall $\left(x_{m}=15 \mathrm{~mm}\right)$. In the following section we examine the effect of the PCM position, $x_{m}$, and the material proprieties of the PCM on the thermal behavior of the wall.

\section{- Effect of the PCM position, $x_{m}$}

In order to investigate the effect of the PCM wall structure on its thermal performance, a study was made by modifying the position of the PCM layer, $x_{m}$, then examining the effect on, $T_{1, i n}, q_{L}, q_{s}$ and temperature swings. Fig. 8 sketches the time wise variation of the concrete/PCM wall temperature for two positions of the PCM layer, $x_{m 1}=15 \mathrm{~mm}$, near to the inner face and $x_{m 2}=150 \mathrm{~mm}$, close to the outer face of the wall. The liquid fraction, $f$, is also presented for a typical days of January. Data analysis shows that the inner temperature relative deviations $\frac{T_{\max }-T_{\min }}{T_{c}}$ are 0.228 and 0.318 for $x_{m 1}$ and $x_{m 2}$, respectively. So it's clear that when the PCM layer is close to the inner face better are the living thermal conditions with less temperature fluctuations. For the two values of the position, $x_{m}$, PCM completely melts at noon $(f=1)$. The PCM remains in liquid state until 20h00. The liquid phase is superheated during about 8 hours for $x_{m 1}$ and 11 hours four $x_{m 2}$. Note that solar radiation are maximum at $12 \mathrm{~h} 00$ and then decreases but ambient temperature continues increasing 2 hours, reach its maxima at $14 \mathrm{~h} 00$ and falls later. This de-emphasis between, $Q_{e x t}$, and, $T_{a}$ and the wall thermal inertia lead to the delayed maxima for the inner temperature one hour latter. In fact, $T_{1, i n}$, reaches the maximum value $23.5^{\circ} \mathrm{C}$ for $x_{m 1}$ and $25{ }^{\circ} \mathrm{C}$ for $x_{m 2}$ at $15 \mathrm{~h} 00$. After $15 \mathrm{~h} 00, Q_{e x t}$ and $T_{a}$ decrease and the superheated liquid PCM releases it heat. The freezing process starts at $21 \mathrm{~h} 00$ for $x_{m 1}$ and at $23 \mathrm{~h} 00$ for $x_{m 2}$. Note that $T_{1, i n}$ remains relatively constant $\left(\sim 18{ }^{\circ} \mathrm{C}\right)$ during the freezing period for $x_{m 1}$. PCM is completely discharged and solidified $(f=0)$ at 07h00. Also it can be seen that, due to the lowest value of ambient temperature, the solid PCM is subcooled during 2 hours for $x_{m 1}$. For the position $x_{m 2}$, PCM doesn't completely solidify and the liquid fraction, $f$, decreases until 0.8 and the PCM remelts again. Therfore, latent heat stored in the day is note completely used during the night for the position, $x_{m 2}$.



Fig. 8: Time wise variation of the concrete/PCM wall temperature and liquid fraction for $x_{m 1}=15 \mathrm{~mm}$ and $x_{m 2}=150 \mathrm{~mm}$

These results are demonstrated using Fig. 9 which gives the latent and sensible heat storage variation for two values of the PCM position, $x_{m}$. Analysis of such figure shows that because the sunrise starts at seven o'clock, the external face of the wall absorbs solar radiations and the concrete transfers 
the energy to the PCM layer by heat conduction. It can be seen that when PCM layer is set near to the outer face, the PCM melts completely at $12 \mathrm{~h} 00(f=1)$ and the melted PCM continue to absorb sensible heat during a large period. During the night the PCM layer situated at this location releases the stored heat, $q_{s}$, by concrete thermal conduction to the ambient and to the indoor. Note that, thermal resistance is proportional to the crossed distance, heat transfer to the indoor weakens and $T_{1, \text { in }}$ is relatively lower for $x_{m 2}$ position comparatively with the value achieved when PCM layer is close to the inner face. It is recommended to setup the PCM layer close to the inner face of the wall to reduce the thermal lose and to achieve more building efficient heating.

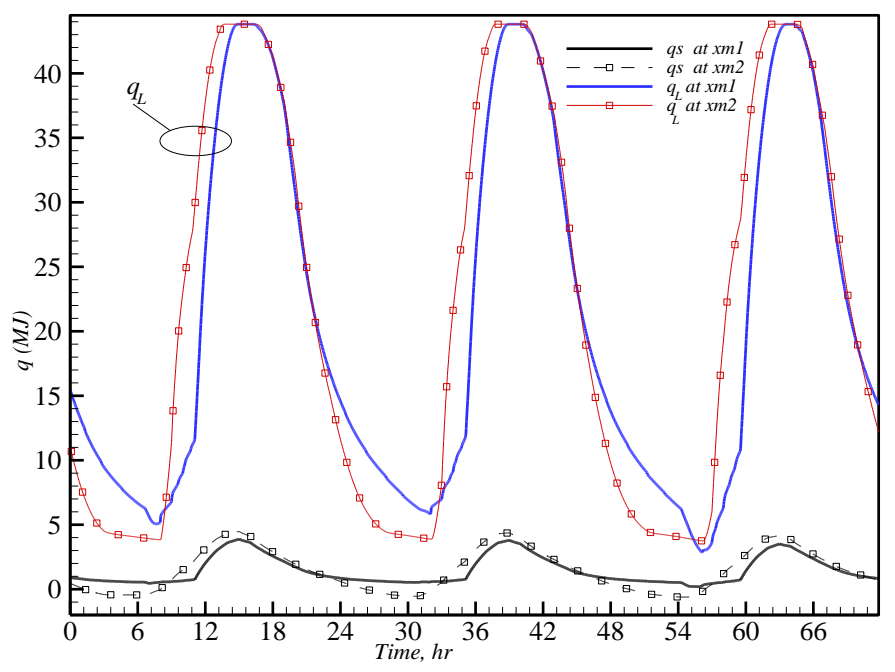

Fig. 9: Variations of the latent heat, $q_{L}$ and sensible heat, $q_{s}$ for positions, $x_{m 1}$ and $x_{m 2}$

\section{- Effect of the PCM properties}

For selecting the PCM to be used in the wall, the following desirable properties were taken into account: high latent heat of fusion per unit mass; chemical stability; melting in the desired operating temperature range $\left(T_{m} \sim 22{ }^{\circ} \mathrm{C}\right)$ small volume change during phase transition; availability in large quantities and low price. In the present study, two kinds of PCM are tested; organic PCMs and Hydrate Salts (Table 1). Fig. 10 gives the simulations results comparing the inner wall temperature for the same volume of used PCMs (Organic PCM, $T_{m}=16{ }^{\circ} \mathrm{C}$ and Hydrate Salt, $T_{m}=21{ }^{\circ} \mathrm{C}$ ). The PCM position and thickness are kept invariant $\left(x_{m}=x_{m 1}=1.5 \mathrm{~cm}\right.$ and $\left.e_{m}=2 \mathrm{~cm}\right)$. For the case with Hydrate Salt, relative deviations $\left(T_{1, \text { in }}-T_{c}\right)_{\max }$ and $\left(T_{1, \text { in }}-T_{c}\right)_{\min }$ are reduced and the inner wall temperature becomes less swing, therefore, more suitable thermal comfort conditions were obtained. This improving in inner temperature is achieved because the melting point of the Hydrate Salt PCM is close to the comfort value (in contrast, $T_{m}=16^{\circ} \mathrm{C}$ for Organic PCM).

Fig. 10 shows also that, Hydrate Salt PCM is completely melted $(f=1)$ at noon and there is no sensible heat in the liquid phase during the day what justify the temperature stability during 4 hours, close to $21.2^{\circ} \mathrm{C}$. Comparatively, $T_{1, \text { in }}$ vary clearly for the Organic PCM case during the same period. Also, it can be remarked that, between $03 \mathrm{~h} 00$ and $09 \mathrm{~h} 00$, the wall temperature decreases from $21.2{ }^{\circ} \mathrm{C}$ to the minimum value which is always greater than $18{ }^{\circ} \mathrm{C}$. Due to the relatively higher value of it thermal conductivity, the Hydrate Salt PCM is completely discharged $(f=0$ at $03 \mathrm{h00}$ ). Furthermore, the nocturnal temperatures registered by Hydrate Salt PCM are relatively greater than those achieved when using Organic PCM. 


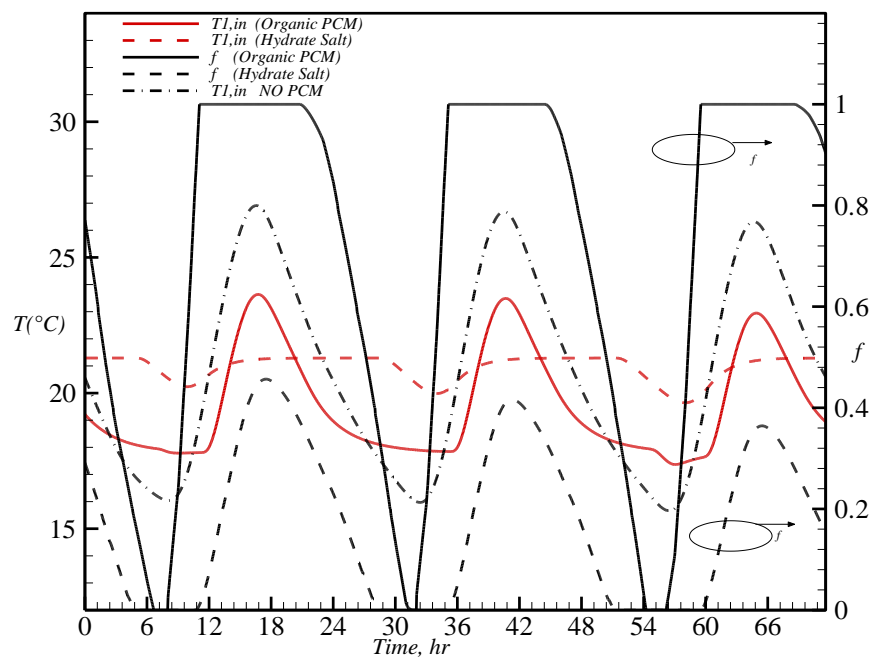

Fig. 10: Wall temperature for Hydrate Salt and Organic PCM

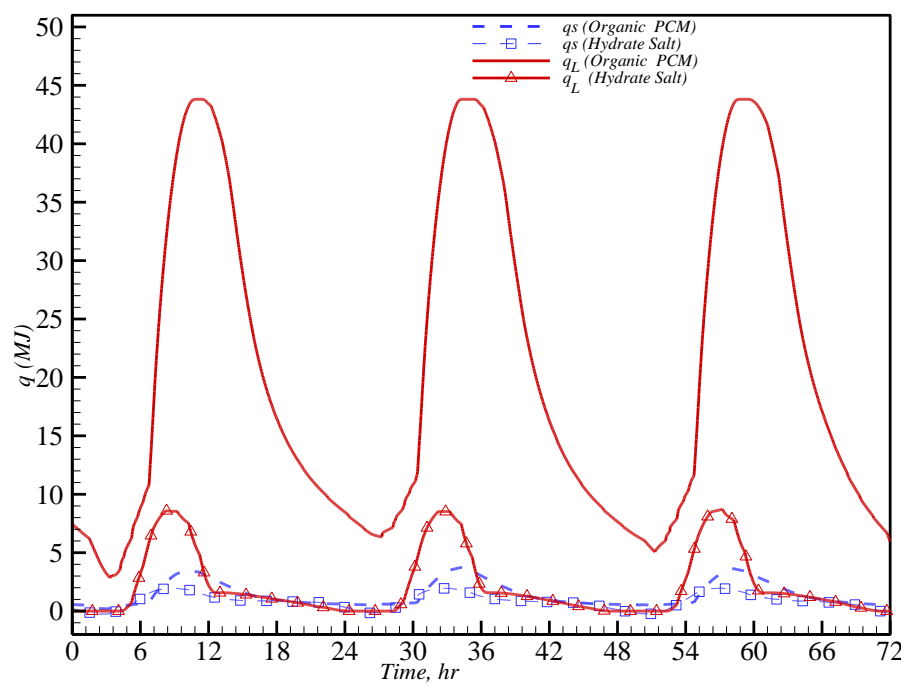

Fig. 11: Sensible and latent heat storage for Hydrate Salt and Organic PCM

Fig. 11 gives the sensible and latent heat storage for Hydrate Salt and Organic PCM. It can be seen that the sensible heat for the Hydrate Salt case is weak between $09 \mathrm{~h} 00$ and $12 \mathrm{~h} 00$. When the melting process is activated the sensible heat $q_{s}$ drops to zero between $13 \mathrm{~h} 00$ and $03 \mathrm{~h} 00$. Due to the night subcooling of the solid phase, $q_{s}$, remains slightly negative for $03 \mathrm{~h} 00$ to noon. Beside, the sensible heat storage for the Organic PCM case is found more important (superheating of the PCM). As a result, more temperature swings.

Fig. 12 represents the thermal gradients, $q_{1, i n}$, occurring between the inner face and indoor air for the two used PCMs. Negative values represent the indoor thermal gain and positive values quantify the thermal lost. Analysis of such figure confirms the above results. Thermal gradient, in the case with PCM, is less than that without PCM. For the Hydrate Salt PCM, a feeble thermal gradients (practically null) are found between $13 \mathrm{~h} 00$ and $03 \mathrm{~h} 00$. So, during this period, there are no thermal loses and the inner temperature remains practically constant. For Organic PCM, thermal gradients are alternatively positive 
and negative and temperature fluctuations are clearly more pronounced. The inner wall gains and loses the heat.

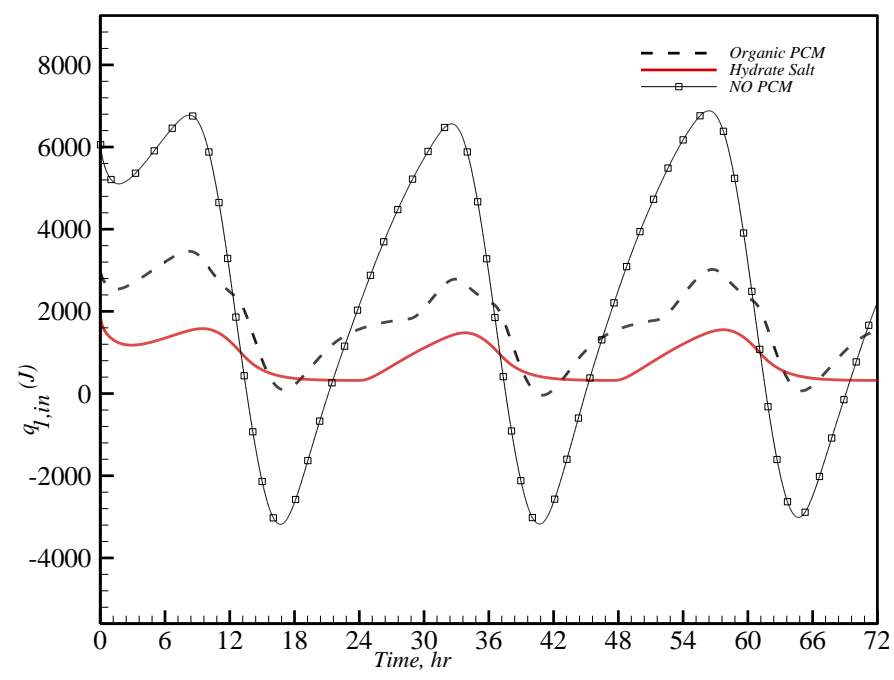

Fig. 12: Thermal gradient, $q_{1, \text { in }}$ for Hydrate Salt and Organic PCM

\section{- Thermal performance analysis}

The performance of the wall with Hydrate Salt as a heating system for the building has been evaluated in terms of Thermal Load Leveling, $T L L$, and daily heating potential, $Q_{h}$, using the following equations [7]:

$$
\left\{\begin{array}{l}
T L L=\frac{\left(T_{i, \text { in }}\right)_{\max }-\left(T_{i, \text { in }}\right)_{\min }}{\left(T_{i, \text { in }}\right)_{\max }+\left(T_{i, \text { in }}\right)_{\min }} \\
Q_{h}=\sum_{t=1}^{24} c_{b}\left(T_{1, \text { in }}(t)-T_{a}(t)\right)
\end{array}\right.
$$

Thermal load leveling, $T L L$, puts a figure on the fluctuations of temperature inside the room. The less the fluctuations the better is the environment for the occupants. In winter, without heating arrangement for thermal comfort requirements, thermal load leveling should have lower value by incorporating heating method due to the increase of $\left(\left(T_{i, \text { in }}\right)_{\max }+\left(T_{i, \text { in }}\right)_{\min }\right)$ and the decrease of ( $\left.\left(T_{i, \text { in }}\right)_{\max }-\left(T_{i, \text { in }}\right)_{\min }\right)$.

Table 2: Thermal load leveling, TLL

\begin{tabular}{ccc}
\hline Day & TLL (With PCM) & TLL (No PCM) \\
\hline 1 & 0.014 & 0.205 \\
2 & 0.023 & 0.253 \\
3 & 0.020 & 0.248 \\
\hline
\end{tabular}

The results for daily variation of thermal load leveling for wall with and without PCM are summarized in Table 2. It can be seen that the value of TLL is maximum for the wall without PCM and it is reduced to about 10 p.c. for composite wall with PCM. The lower values of thermal load leveling indicate the decrease in the fluctuations of inner face and, thereby, there occurs an improvement of thermal comfort environment in the building. 
Also, the daily variations of total heating potential $Q_{h}$ obtained from PCM wall for typical cold days were calculated and have been accumulated in Table 3. From the results, it is found that the heating potentials obtained in case with PCM wall were higher as compared to an ordinary wall.

Table 3: Total heating potential

\begin{tabular}{ccc}
\hline Day & $\begin{array}{c}\boldsymbol{Q}_{h}(\mathrm{MJ}) \\
\text { (With PCM) }\end{array}$ & $\begin{array}{c}\boldsymbol{Q}_{h}(\mathrm{MJ}) \\
\text { (No PCM) }\end{array}$ \\
\hline 1 & 6.165 & 5.817 \\
2 & 5.962 & 5.645 \\
3 & 6.226 & 5.912 \\
\hline
\end{tabular}

\section{Conclusion}

A composite Concrete/PCM wall was modeled using the enthalpy method. The numerical code was validated against published experiments. The thermal performances of the proposed composite wall, used for heating application, were monitored under typical working conditions. Attention was focused on the impact of the PCM category and wall structure on the inner temperature. It was emerged that the PCM/concrete wall is able to provide good performance. The thermal conditions of the indoor environment achieved when the PCM layer is set close to the inner face of the wall have resulted to be considerably improved compared to a concrete wall without PCM. Sub-cooling and superheating occur when PCM doesn't melt or solidify immediately. This problem should be investigated. The analysis has shown that particular care should be taken when choosing PCM, especially, the melting temperature. The good PCM choice is when the material melts completely before the sunset and resolidifies completely before the sunrise. Phase change materials that have a melting point near to comfort temperature and better thermal conductivity (hydrate salts) can replace thermal mass and lead to a significant reduction of the building energy consumption. More research is still needed to demonstrate the thermal performance and economics of the proposed heating system.

\section{Acknowledgements}

The present work was accomplished according to the InnoTherm II, program- IRESEN- Morocco.

\section{Nomenclature}

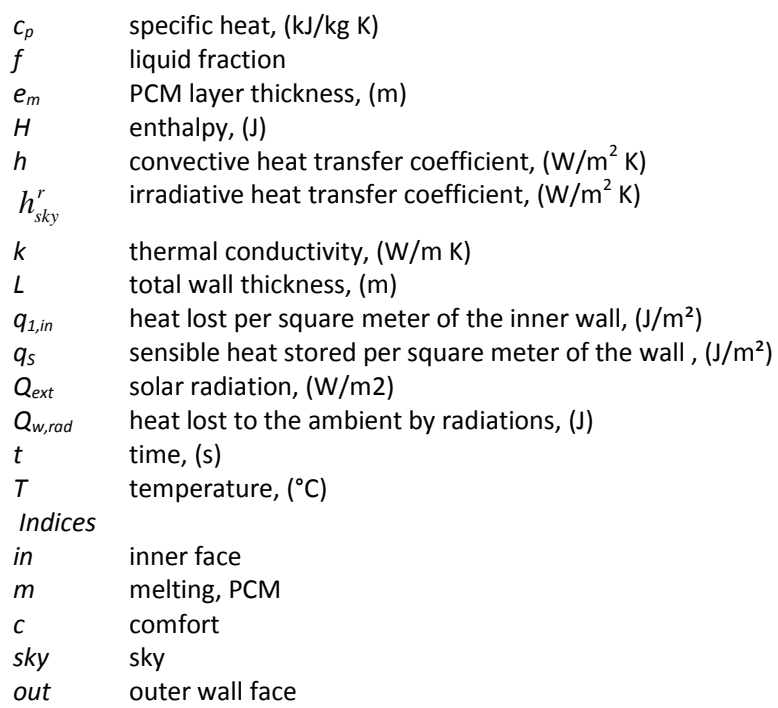






\section{References}

[1] B. Zalba, J.M Marín, L.F Cabeza, Mehling H. Review on thermal energy storage with phase change: materials, heat transfer analysis and applications. Applied Thermal Engineering;23:251e83, 2003.

[2] M. Faraji, M. Najam, M. El Alami, Z. Bouhssine, F. Berroug, E.K. Lakhal, M. El Omari, P. Rochus. Numerical Analysis of the Passive Heating of Building integrated Phase Change Materials. Numerical Heat Transfer, Gliwice-Wrocław, Poland, Septembre 4-6, 2012.

[3] Li. B. Z, Zhang C.L, Deng A. Study on improving indoor thermal environment in light weight building combining PCM wall and nighttime ventilation. Journal of Civil Architectural \& environmental Engineering 31(3) 2009.

[4] J.Paris, Villain, J.-F Houle. Incorporation of PCM in wallboards: a review of recent developments. In: Proceedings of the First World Renewable Energy Congress, September, Reading, UK, pp. 2397-2401, 1990.

[5] K. Peippo, P. Kauranen, P.D. Lund, A multicomponent PCM wall optimized for passive solar heating, Energy and Buildings 17 259-270, 1991.

[6] D.A. Neeper, Thermal dynamics of wall board with latent heat storage, Solar Energy 68 393-403, 2000.

[7] M. Faraji, Numerical computation of solar heat storage in phase change material/concrete wall. International Journal of Energy and Environment, vol 5, (3).353-360, 2014.

[8] M. Zhang, A.M. Medina, B.J. King, Development of a thermally enhanced frame wall with phase change materials for on-peak air-conditioning demand reduction and energy savings in residential buildings, International Journal of Energy Research, Green heck Fan Corporation, Schofield, WI, U.S.A, 2005.

[9] F. Berroug, E.K. Lakhal, M. El Omari, M. Faraji, H. El Qarnia, Thermal performance of a greenhouse with a phase change material north wall, Energy and Buildings 43 3027-3035, 2011.

[10] A.Athienities, Y.Chen The effect of solar radiation on dynamic thermal performance of floor heating systems. Solar Energy 69(3):229-37, 2000.

[11] K Lin, Y. Zhang, X. Xu, H. Di, R. Yang, P. Qin, Experimental study of under-floor electric heating system with shape-stabilized PCM plates, Energy and Buildings 37 215-220, 2005.

[12] K.A. Ismail, J.R. Henriquez, Thermally effective windows with moving phase change material curtains, Applied Thermal Engineering 21 1909-1923, 2001.

[13] A.K. Athienitis, C. Liu, D. Hawes, D. Banu, D. Feldman, Investigation of the thermal performance of a passive solar test-room with wall latent heat storage, Building Environment 32 405-410, 1997.

[14] P. Brousseau, M. Lacroix, Study of the thermal performance of a multi-Layer PCM storage unit, Energy Conversion Management 37 599-609, 1996.

[15] V.R. Voller and S.Peng An enthalpy formulation based on an arbitrarily mesh for solution of the Stefan problem. Computational Mechanics, 14:492-502, 1994.

[16] W.C. Swinbank, Long-Wave radiation from clearskies, Quarterly Journal of the Royal Meteorological Society 381(89) 339-348, 1963.

[17] Patankar, S.V., Numerical Heat Transfer and Fluid Flow, Hemisphere, 1983

[18] Dincer, M.A. Rosen, Thermal energy storage systems and applications, John Wiley \& Sons, Chichester (England), 2002.

[19] Energy Efficiency and Ren. Energy office of build. Technol, U S Dep. of Energry. Energy Plus testing with Building Thermal Envelope Test. ANSI/ASHRAE Standard Energy Plus, 2009 